\title{
A Brief Talk on the Construction of New Countryside in Pearl River Delta
}

\author{
Deyu Chen ${ }^{1, *}$ and Jing Guo ${ }^{2}$
}

\author{
${ }^{1}$ Guangzhou college of commerce, Guangzhou, China \\ ${ }^{2}$ Yichun University, Yichun, Jiangxi Province, China \\ *Corresponding author. Email: chendeyu666@163.com.
}

\begin{abstract}
The issue of agriculture, rural areas and farmers has always been a key issue in our country's modernization drive. Since the reform and opening up, China's rural construction has made great achievements, especially in the Pearl River Delta, relying on the superior geographical position and the country's preferential policies to develop rapidly. At present, however, most of them have met the bottleneck of further development. In view of the important strategic decision of building a new socialist countryside recently made by the Central Committee at the Third Plenary Session of the 16th Central Committee, this paper provides some suggestions on how to build a new socialist countryside under the new situation for the Pearl River Delta.
\end{abstract}

Keywords: Pearl River Delta, New countryside, Construction.

\section{INTRODUCTION}

New Rural Construction is an important measure to promote rural development in China. The Pearl River Delta is seen as a land of gold and silver, with per capita GDP of more than $\$ 8,000$ in 2005 in places such as Dongguan and Shunde. Governments are rich, people are rich, and the countryside in the Pearl River Delta has changed beyond recognition. However, the problems to be solved in the construction of a new countryside in the Pearl River Delta with the rapid development of industrialization and urbanization are obviously different from those in the central and western regions of China, some problems and contradictions are more urgent and prominent than those in the vast countryside of Midwestern Sectional Figure Skating Championships. For example: In recent years, in the process of promoting the overall development of urban and rural areas and building a new countryside, the following life problems and long-term employment problems of the landless peasants, the shortage of land resources and the construction of the peasants' houses, the problems of the small-rich being at ease and the cultivation of innovative consciousness and pioneering spirit, the problems of clear property rights and property rights reform of the rural collective economy, the fund gap and financial pressure of social security, the weakness of the rural socialized service system, the rapid economic growth and the difficulty of resources and environment restrict the construction of the new countryside. The follow-up life and long-term employment of land-lost farmers in the Pearl River Delta (PRD) farmers "upstairs" (living in apartments) easy employment "difficult", land-lost farmers employment problem is very difficult and prominent.

Therefore, actively promoting the new rural construction is a major strategic plan and a long-term historical task made by the CPC Central Committee and the State Council in the light of national conditions and people's feelings. In recent years, the Party Committee and the provincial government of Guangdong Province have been stepping up the construction of new countryside. All parts of the Pearl River Delta have conscientiously carried out the deployment of the central and provincial Party committees and provincial governments, made new rural construction an important part of the work of "agriculture, rural areas and farmers", constantly increased investment and made solid progress in various construction projects, and achieved remarkable results, has created many valuable experiences for the whole province. In particular, Zhuhai and other places to promote the construction of happy villages, beautiful villages, with characteristics, bright spots, by the relevant departments of the state and the community's wide attention and recognition, played a model role in the province. 


\section{THE CONNOTATION OF THE NEW COUNTRYSIDE AND THE CHARACTERISTICS OF PEARL RIVER DELTA RURAL DEVELOPMENT}

The "new Socialist Countryside" refers to the social state under the socialist system, which reflects the rural society based on the economic development and marked by the overall social progri8ess. It mainly includes the following aspects: First, to develop the economy and increase income. This is the first prerequisite for building a new socialist countryside. Income will be increased by changing the old mode of production, upgrading new rural production tools, increasing production and efficiency, increasing crop variety and improving crop quality, and expanding the marketing environment. Second, expand public welfare and promote harmony. We will guarantee the right to education for our children and raise the level of education in rural areas so that every child will have the opportunity to read. Strengthening the social security system and improving the quality of social security. Overall planning of urban and rural development to realize the integration of urban and rural development. Third, we should build villages and towns and improve the environment. The old houses will be upgraded to improve people's awareness of garbage classification and environmental protection. The polluted water environment in the countryside will be remedied. Villagers will be encouraged to plant more trees to protect the ecological environment. Fourth, we should cultivate farmers and improve their quality. To strengthen the ideological and moral construction, improve the ideological and moral level of villagers; to strengthen the rural cultural construction, enrich the spiritual and cultural life of farmers.

Specifically speaking, the so-called "new countryside" includes five aspects, namely the new house, the new facility, the new environment, the new farmer, the new fashion. These five indispensable, together constitute an important part of the new rural construction. On the one hand, we should build a "resource-saving and environment-friendly" living environment according to the local rural environment; on the other hand, we should improve the local infrastructure and raise the living standards of farmers; and on the other hand, we should improve the ideological and cultural quality of farmers, so that the farmers with modern quality, become an ideal, cultural, moral, have the probability of the "four have farmers", to strengthen the rural spiritual civilization, building a better rural society.

Being at the forefront of reform and opening up, the Pearl River Delta is at the forefront of national development because of its favorable geographical environment and preferential policies. The development of these areas depends on the local rich natural resources to develop rapidly. Many migrants are attracted by the local geography and the booming economy, and they earn considerable income by renting and working in these places. However, with the development of economy and more and more migrant workers, land resources are reduced, and the lack of national policy support, the sustainable development of these places has been hindered.

\section{THE TRAIN OF THOUGHT OF THE PEARL RIVER DELTA}

In the construction of a new socialist countryside in the comprehensive conditions, the Pearl River Delta has occupied a huge advantage in the country. However, it is undeniable that the overload of resource consumption and rapid economic development, making the Pearl River Delta also face huge challenges and obstacles. One is the scarcity of resources. With the rapid economic development, the level of industrialization is also constantly improving, followed by industrial pollution, air quality gradually reduced, water quality gradually deteriorated. If we do not reform the industrial construction and strengthen the environmental supervision, it will seriously restrict the new rural construction. Second, the system lags behind. There are unreasonable and nonstandard problems in the rural system, which hinder the development of the new rural construction. So the rural areas want to develop, but also need to improve the rural institutional mechanism, strengthen the strength of rural governance. Thirdly, there is a shortage of talents. Compared with urban talent structure, the imbalance of rural talent structure seriously hinders the development of new rural construction. Young people generally have a low level of education and cultural quality, and obviously can not keep up with the pace of development of the times. Moreover, the township's lack of professional and technical personnel, which has become the reason for the development of new rural construction difficult. Fourth, the lack of education. Many rural children are not educated, and long-term living in the countryside, resulting in their vision is small, do not know how to communicate with the outside world. The development of the countryside needs the development of each person, which enlightens us to strengthen the education security of the countryside and improve the education level of the peasants. Fifth, the problem of ecological deterioration. In recent years, with the rapid development of economy, industrialization and urbanization, the environmental pollution and ecological damage in the Pearl River Delta has also been a problem. It can be said that the Pearl River Delta's air pollution, water pollution, soil pollution and other comprehensive coverage. Many people breathe no fresh air, drink no clean water, even the living environment has been destroyed, leading to their homelessness. These have a direct impact on social harmony and 
stability, and have become one of the key issues in the new rural construction. Faced with so many "hard wounds", has been in a higher development platform of the Pearl River Delta, the new rural construction should choose what kind of path and model? To sum up, the Pearl River Delta needs to start from the following aspects:

1. Build an urban-rural talent pool. We should tap talents, attach importance to the training of talents, be good at grasping social management, be good at doing mass work, and attach importance to humanities and ecological construction, at the same time, we should re-establish and improve the service of the new rural construction of modern education, science and technology and cultural talent. We should highly train young people with knowledge, ability and prospects to join the party, change the ranks of Party members and cadres in rural areas as soon as possible, and give full play to the role of the battle fortress, to form a dynamic, appealing and cohesive force of the main body of new rural construction.

2. Strengthen the training and education work, improve the comprehensive quality of farmers, cultivate new farmers. The key to the new rural construction is to improve the quality of farmers. We must further increase the investment in rural education and training, and provide farmers with training in various aspects, including vocational skills training and training in legal knowledge, entrepreneurial skills and official document writing, so as to enhance their quality, we will effectively strengthen the training of rural labor forces, vigorously develop rural vocational education, comprehensively improve the cultural quality and work skills of farmers, and provide high-quality construction subjects for the construction of a new countryside. At the same time, we will attach great importance to solving the Day Labor problem; we will further strengthen employment services and the protection of the rights and interests of migrant workers.

3. Accelerating the reform of rural institutions and mechanisms. We should improve the existing system and mechanism in rural areas, further deepen the rural reforms and innovate the system and mechanism. We should establish and improve the rural social security system as soon as possible, improve the living conditions of rural residents, promote the development of rural economy, ease various social contradictions in rural areas, and provide security for the promotion of new rural construction.

4. Strengthen the integration of resources, improve public infrastructure, advocate resource conservation and ecological protection. Pay attention to the effective integration and protection of resources, implement the transformation of old villages, improve public infrastructure, and create an urbanized, humane ecological environment. Raising villagers'awareness of environmental protection in saving resources. We must balance urban and rural development, balance and coordinate development, balance population, resources and environment, promote sustainable and coordinated development, and strengthen ecological protection.

5. We will actively promote urbanization and increase the space for farmers to find employment and increase their incomes. Take the road of urbanization with Chinese characteristics, follow the law of Urban Development, speed up the pace of urbanization, promote the healthy development of urbanization. In the process of urbanization, villagers can set up retailers, open restaurants and hair salons, or try to increase their income by investing in stocks and funds. Speeding up the construction of agricultural modernization and increasing the income of farmers.

6. Expand democracy at the grassroots level and advance the development of democracy and the legal system in rural areas. First, strengthen the leadership of the party and promote the construction of democracy and the legal system at the grass-roots level in rural areas. Second, pay close attention to the education of popularizing law in rural areas, constantly improve the legal quality of farmers, and cultivate their awareness of democracy and legal system. Third, the implementation of villagers'self-governance, the establishment of rules and regulations. Fourth, we will strengthen comprehensive management to maintain social and economic stability in rural areas. We will intensify the investigation and punishment of cases of violations of laws and disciplines in rural areas. Fifth, give full play to the role of villagers'self-governing organizations; strengthen the villagers'self-management and self-service functions. Promoting the construction of new countryside on the track of systematization and standardization.

\section{CONCLUSION}

The industrialization and urbanization of the Pearl River Delta are already on a high development platform, and the problems to be solved in the new rural construction are obviously different from those in the central and western regions of China. The Path and mode of new rural construction cannot be separated from the background of Social Economic Development and resource environment, and should be driven by industrialization, urbanization and Agricultural Industrialization. To this end, on the one hand, we must 
re-examine the current problems of industrialization and urbanization, truly integrate new rural construction into them, drive urbanization with industrialization and fight against corruption in agriculture with industry; on the other hand, we must vigorously develop the rural economy, we will give full play to the advantages of local industries in rural areas and promote rural industrialization, agricultural industrialization and urbanization. Only by combining inside and outside can we effectively promote the construction of new countryside, realize the win-win interaction between urban and rural areas, achieve the integration of urban and rural areas, and then push the economic and social modernization of the whole region.

First, more attention to people-oriented, Huinong District rich people. People-oriented, benefiting farmers and enriching the people is the starting point and foothold of the new rural construction. The main body of the new rural construction is the peasants, who believe the masses, respect the masses, rely on the masses, serve the masses and benefit the masses. The reason why the building of a new countryside in Guangdong has become a popular project for the broad masses of farmers is that the most important thing is that the broad masses of party members and cadres work steadfastly and avoid ostentation, from the most urgent, the most direct, the most concerned farmers living, water supply, security, environmental sanitation, sewage and garbage treatment, so that farmers get real benefits. Second, more emphasis on ecological priority, sustainable use of resources. Guangdong has a large population, a relative lack of resources, and a large conflict in human settlements. In the construction of the new countryside, Guangdong has always adhered to the requirement of saving, intensive, efficient and sustainable utilization of resources, leaving no hidden danger for the future development. Third, pay more attention to cultural heritage and cultivate new-type farmers. The new rural construction is not only the material construction and economic construction, but also the cultural inheritance and spiritual civilization construction. Lingnan culture, as the representative of excellent local culture, is essentially an agricultural culture and the common spiritual home of Guangdong people at home and abroad. The new rural construction in Guangdong not only reshaped the face of the new generation of Lingnan farmers, but also passed down the Lingnan rural regional culture and realized the modern local development of Lingnan culture. The construction of the new countryside is also closely linked with the improvement of the quality of the peasants, and many efforts have been made to improve their cultural quality, scientific quality and civic awareness, and to cultivate new-type peasants. Fourth, pay more attention to the overall planning; promote the synergy between the development of villages, mutual development and characteristics of development, dislocation development of the combination. Compared with the past, the new rural construction in Guangdong pays more attention to the linkage mechanism construction and the synergy effect between the villages in a larger area. This policy change has proved to be correct and has been fully affirmed in practice.

In the next step, Guangdong also needs to pay more attention to the sustainable utilization and organic integration of the ecological, cultural and agricultural resources of Guangdong Province on the basis of inheriting and developing Lingnan Culture, with ecological protection as the priority principle, to transform the actual and potential resource advantages into development advantages, not only to improve, upgrade and protect the rural human settlement environment in an all-round and sustainable way, but also to combine the continuous increase of farmers'income and the overall well-off life in the countryside, to completely change the backward situation in rural areas, and promote the early realization of a new pattern of rural development in the vast number of rural areas, with internal development dynamics, self-balanced coordination, multi-dimensional coordination and good governance, the rural areas in Guangdong Province should be the model areas of the new socialist countryside with Distinctive Lingnan Culture, human history, natural ecology, rural scenery, residential features, rural tourism and industrial characteristics.

\section{REFERENCES}

[1] Sun Yan. Socialist New Rural Planning Practice and inspiration [j]. Urban planning newsletter, 2019, (06).

[2] Liu gang et Al., Reflections on building a new socialist countryside in China [J]. Rural Economy, 2019, (07).

[3] $\mathrm{Yu}$ Yongsong, thoughts on promoting urban-rural integration and building a new socialist countryside. Journal of CPC Hefei Municipal Party School, 2018, (02).

[4] Qiu Shuhong, the Pearl River Delta of the new rural construction. Wind in the sea, 2019, (3). 